\title{
Bone Mineral Density and Vitamin D Status in Children with Chronic Neurological Syndromes-Clinical Observations
}

\author{
Elżbieta Jakubowska-Pietkiewicz¹, Gabriela Orzechowska', Elżbieta Woźniak, Joanna Kudzin²*, \\ Ewa Toporowska-Kowalska²
}

${ }^{1}$ Department of Paediatric Propaedeutics and Bone Metabolism Diseases, Medical University of Lodz, Lodz, Poland ${ }^{2}$ Department of Paediatric Allergology, Gastroenterology and Nutrition, Medical University of Lodz, Lodz, Poland

Email: `jkudzin@gmail.com

How to cite this paper: Jakubowska-Pietkiewicz, E., Orzechowska, G., Woźniak, E., Kudzin, J. and Toporowska-Kowalska, E. (2018) Bone Mineral Density and Vitamin D Status in Children with Chronic Neurological Syndromes-Clinical Observations. Case Reports in Clinical Medicine, 7, 315-323.

https://doi.org/10.4236/crcm.2018.75029

Received: March 6, 2018

Accepted: May 7, 2018

Published: May 10, 2018

Copyright (c) 2018 by authors and Scientific Research Publishing Inc. This work is licensed under the Creative Commons Attribution International License (CC BY 4.0).

http://creativecommons.org/licenses/by/4.0/

Open Access

\begin{abstract}
Background: Some of the risk factors for osteoporosis population include: chronic immobilisation, insufficient dietary supply of calcium and vitamin D, decreased physical activity and long-term pharmacological treatment (glucocorticoids, anticonvulsant drugs). In disabled children and adolescents, the negative impact of these factors may cumulate to considerably impair the quality of life. Objectives: The aim of our study was to assess the vitamin D status and bone mineral density in children with chronic neurological syndromes. Material and Methods: A total of 34 children between 3 and 18 years of age were examined: 9 children with muscular dystrophy, 17 with cerebral palsy and 8 with lumbar myelomeningocele. All the subjects underwent the following assessments: measurement of the concentration of the hepatic metabolite of vitamin $\mathrm{D}$ and total body less head and/or lumbar spine densitometry by dual energy X-ray absorptiometry (DEXA). Low bone mass or low bone mineral density was diagnosed if the Z-score value was found to be equal to or below -2.0. Results: Indications for the above tests were chronic immobilisation or motor activity restriction, and-in 10/34 children-femoral or vertebral fracture. Vitamin D deficiency $(<30 \mathrm{ng} / \mathrm{ml})$ was detected in $27 / 33$ patients $(>81 \%)$. Low bone mass on densitometry was demonstrated in $27 / 34$ and osteoporosis in 10/34 subjects (Z-score $\leq-2.0$ ). Conclusion: Bone densitometry should be included in the standard of care for children with chronic neurological syndromes, and early detection of low bone mass should be an indication for treatment with calcium and vitamin $\mathrm{D}$.
\end{abstract}

\section{Keywords}

Children, Densitometry, Cerebral Palsy, Muscular Dystrophy, Myelomeningocele 


\section{Introduction}

Neuromuscular and neurodevelopmental disorders in children interfere with the normal physical activity and nutrition, and rendering it is completely impossible; the progressive nature of these disorders may lead to low bone mass and/or osteoporosis [1] [2]. The group at a particularly high risk of bone mineral loss includes children with cerebral palsy and muscular dystrophy and patients with motor activity restrictions secondary to permanent or progressive destruction of the locomotor system [3]. In all the paediatric chronic diseases which may affect the skeletal system, densitometric assessment of the bone is indicated [1]. This also applies to diseases which lead to motor disability. The diagnosis of low bone mineral density may also indicate an increased risk of clinically significant bone fracture and the need for treatment with vitamin $\mathrm{D}$ and calcium supplements and even with bisphosphonates [4] [5].

The aim of our study was to assess bone mineral status and vitamin D status in disabled children and adolescents with cerebral palsy, muscular dystrophy, and with myelomeningocele.

\section{Material and Methods}

The observations cover the period 2005-2015 and concern 34 children between 3 and 18 years of age. A total of 9 children were diagnosed with muscular dystrophy and 17 with cerebral palsy. A total of 8/34 children had undergone neurosurgery as infants for lumbar myelomeningocele with ventriculoperitoneal shunt implantation for hydrocephalus accompanying the myelomeningocele. The children were referred to the Department of Paediatric Propaedeutics and Bone Metabolic Diseases from specialist outpatient clinics for evaluation of bone mineral metabolism.

The inclusion criteria involve: chronic diseases like muscular dystrophy or cerebral palsy or myelomeningocele, age 3 to 18 years old, skeletal system complaints (bone pains and/or fracture), lack of vitamin D supplementation 3 months before our study. The exclusion criteria contain: total parenteral nutrition in patient's medical history and endocrinological disorders.

Anthropometric measurements of weight and height were performed in each subject according to the generally accepted methodologies and the results were plotted on growth charts [6]. Measurements of basic parameters of calcium and phosphate metabolism, including serum concentration of the hepatic metabolite of vitamin D (i.e. 25-hydroxy vitamin D [25OHD]) by Elisa method, were performed in each subject [7]. In line with the guidelines developed for the Polish population of children, vitamin D deficiency was diagnosed at values below 30 $\mathrm{ng} / \mathrm{ml}$ [8]. PTH levels were also measured by chemiluminescent microparticle immunoassay (CMIA) method.

Each of the patients underwent total body less head (TBLH) and/or anteroposterior (AP) lumbar spine (L1-L4) dual energy X-ray absorptiometry (DEXA) using Lunar Prodigy Advance (GE Healthcare). The duration of the DEXA scan 
was 4 minutes for the TBLH and 30 seconds for the AP spine programme. The radiation doses were: $0.37 \mu \mathrm{Gy}$ and $37 \mu \mathrm{Gy}$, respectively, and the measurement error was below $1 \%$ for both programmes $(\mathrm{CV}<1 \%)$.

In 1/34 children below 5 years of age, the Infant option was used. Low bone mineral density (low bone mass) was diagnosed if the $\mathrm{Z}$-score values were equal to or below -2.0 , and when this was accompanied by the presence of long bone and/or vertebral fractures, the diagnosis of osteoporosis was established [1]. In patients with weight or height deficiency (measured values below the 3rd percentile), bone densitometry results were expressed in terms of the child's biological age [1] [9] [10].

The study was approved by an Ethics Committee Medical University of Lodz, Poland (RNN/144/03/KE 2003).

\section{Results}

Somatic growth assessment and the number of bone/vertebral fractures in the study subjects are given in Table 1 .

According to it, weight and height deficiencies were most commonly present in patients with cerebral palsy (8/17 children). In 4/8 children with myelomeningocele, height deficiency was present and in 2/9 children with muscular dystrophy a body mass below the 10th percentile was observed. Bone fractures were most commonly diagnosed in children with cerebral palsy (6/17), with two boys being diagnosed with both thoracic and lumbar spine fractures (T12, L3-5). In patients with myelomeningocele, a total of 8 bone fractures were noted with 2 children suffering femoral fracture twice. Individual concentrations of the hepatic metabolite of vitamin D (25OHD) are given in Figure 1.

Table 1. Somatic growth assessment and the number of bone/vertebral fractures in the study subjects.

\begin{tabular}{|c|c|c|c|}
\hline Clinical data & Muscular dystrophy $(\mathrm{n}=9)$ & Cerebral palsy $(\mathrm{n}=17)^{*}$ & Myelomeningocele $(\mathrm{n}=8)$ \\
\hline \multirow[t]{2}{*}{$\begin{array}{l}\text { Bone/vertebral } \\
\text { fractures }\end{array}$} & 1 & 6 & 3 \\
\hline & \multicolumn{2}{|r|}{ Weight } & \\
\hline$<10$ centile & 2 & 8 & 1 \\
\hline 10 - 90 centile & 6 & 8 & 7 \\
\hline \multirow[t]{2}{*}{$>90$ centile } & 1 & - & - \\
\hline & \multicolumn{2}{|r|}{ Height } & \\
\hline$<10$ centile & 1 & 8 & 4 \\
\hline 10 - 90 centile & 8 & 8 & 4 \\
\hline$>90$ centile & - & - & - \\
\hline
\end{tabular}

*no data in one patient. 


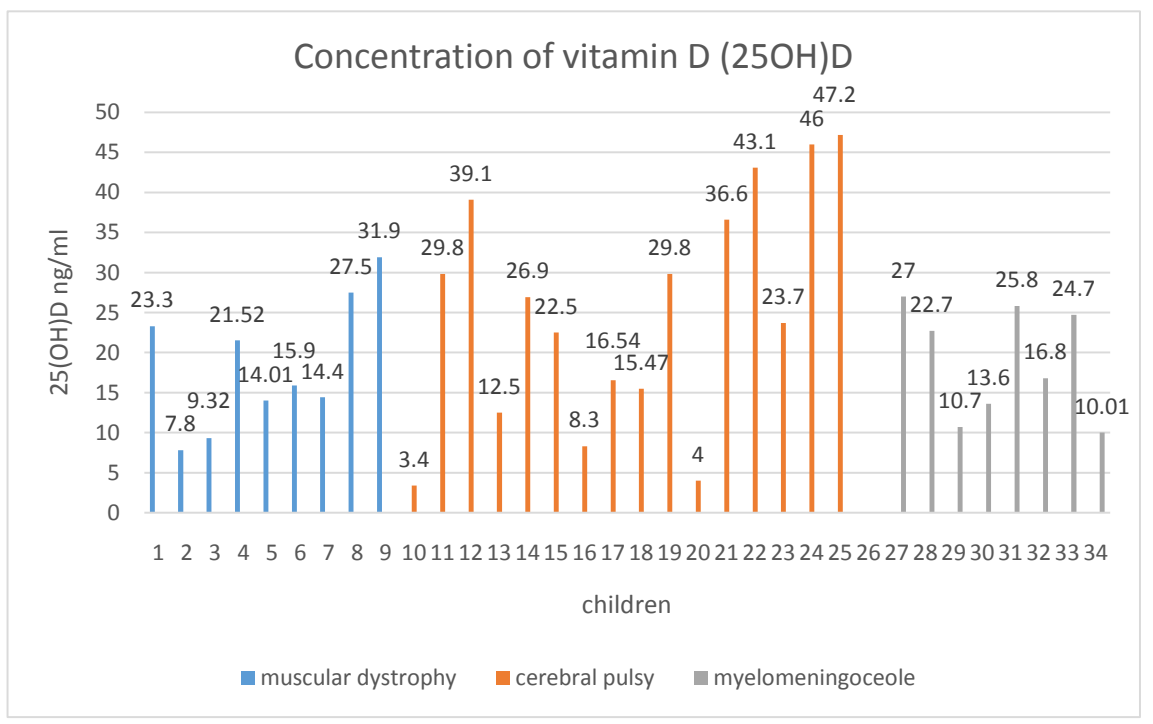

Figure 1. Individual concentrations of the hepatic metabolite of vitamin D (25OHD) in all patients.

In total, vitamin $\mathrm{D}$ deficiency was demonstrated in 27 patients and in $5 / 34$ the level was below $10 \mathrm{ng} / \mathrm{ml}$. Results of the other tests of calcium and phosphate metabolism, including PTH concentration, were within the respective reference ranges. An exception was a boy with cerebral palsy, who was found to be profoundly hypocalcaemic (he required intravenous administration of calcium, although clinically he was asymptomatic).

Individual values of $\mathrm{Z}$-score in the TBLH and/or lumbar spine DEXA scan in the study subjects are given in Tables 2-4. According to Table 2, in children with muscular dystrophies, $6 / 9$ children below 10 years of age were found to have bone mineral density with a Z-score of less than -2.0 .

Another 13/17 patients with cerebral palsy (Table 3) also had Z-score values in the TBLH and/or lumbar spine DEXA scan of less than -2.0 , although in 6 children the assessment was performed based on one programme only.

In Table 4, individual results of densitometry in patients with a history of surgery for myelomeningocele are shown. In 7/8 children, the Z-score in lumbar spine DEXA was equal to or below -2.0. In 1 patient, a 3-year-old boy, the scan was taken in the Infant option and the BMD was $0.522 \mathrm{~g} / \mathrm{cm}^{2}$.

\section{Discussion}

Bone densitometry is part of the complex assessment of bone status in children and adolescents at increased risk of bone fracture [1] [9] [10]. This is particularly the case in patients with chronic inflammatory diseases, nutrition disorders, patients on long-term treatment with glucocorticosteroids and with markedly reduced motor activity [1] [3]. In the presented group of children, an indication for performing densitometry was motor activity restriction resulting from the underlying condition: cerebral palsy, muscular dystrophy, a history of surgery for myelomeningocele. 
Table 2. Individual values of densitometric examination (BMD, Z-score in the TBLH and/or lumbar spine DEXA scan) in the subjects with muscular dystrophies.

\begin{tabular}{|c|c|c|c|c|c|c|}
\hline $\begin{array}{l}\text { Participant } \\
\text { no }\end{array}$ & $\begin{array}{l}\text { Type of muscular } \\
\text { dytrophy }\end{array}$ & $\begin{array}{c}\text { Age } \\
\text { (years)/sex }\end{array}$ & $\begin{array}{c}\text { TBLH } \\
\operatorname{BMD}\left(\mathrm{g} / \mathrm{cm}^{2}\right)\end{array}$ & Z-score & $\begin{array}{l}\text { BMD spine } \\
\left(\mathrm{g} / \mathrm{cm}^{2}\right)\end{array}$ & Z-score \\
\hline 1 & $\mathrm{DMD}^{*}$ & $8 / \mathrm{M}$ & 0.58 & -0.5 & - & -2.0 \\
\hline 2 & $\mathrm{DMD}$ & $7 / \mathrm{M}$ & 0.73 & -0.93 & 0.61 & -0.19 \\
\hline 3 & $\begin{array}{c}\text { Progressive muscular } \\
\text { dystrophy }\end{array}$ & $15 / \mathrm{M}$ & - & - & 0.49 & -5.6 \\
\hline 4 & $\begin{array}{c}\text { Progressive muscular } \\
\text { dystrophy }\end{array}$ & $10 / \mathrm{F}$ & 0.76 & -1.1 & 0.58 & -1.4 \\
\hline 5 & DMD & $11 / \mathrm{M}$ & 0.58 & -2.8 & 0.61 & -1.6 \\
\hline 6 & DMD & $10 / \mathrm{M}$ & 0.62 & -2.1 & 0.69 & -0.8 \\
\hline 7 & $\mathrm{DMD}$ & $12 / \mathrm{M}$ & - & - & - & -4.3 \\
\hline 8 & $\begin{array}{l}\text { Spine muscular } \\
\text { atrophy }\end{array}$ & $14 / \mathrm{F}$ & 0.7 & -2.9 & - & - \\
\hline 9 & $\begin{array}{l}\text { Spine muscular } \\
\text { atrophy }\end{array}$ & $7 / \mathrm{M}$ & 0.87 & 0.67 & 0.05 & -6.31 \\
\hline
\end{tabular}

${ }^{*}$ DMD-Duchenne muscular dystrophy.

Table 3. Individual values of densitometric examination (BMD, Z-score in the TBLH and/or lumbar spine DEXA scan) in patients with cerebral palsy.

\begin{tabular}{|c|c|c|c|c|c|}
\hline Participant no & Age (years)/sex & $\begin{array}{c}\mathrm{BMD}\left(\mathrm{g} / \mathrm{cm}^{2}\right) \\
\text { TBLH }\end{array}$ & Z-score & $\begin{array}{l}\text { BMD spine } \\
\left(\mathrm{g} / \mathrm{cm}^{2}\right)\end{array}$ & Z-score \\
\hline 10 & $15 / \mathrm{F}$ & 0.65 & -4.0 & 0.71 & -3.5 \\
\hline 11 & $15 / \mathrm{M}$ & 0.54 & -3.1 & 0.55 & -3.3 \\
\hline 12 & $3 / \mathrm{F}$ & 0.52 & 0.3 & 0.52 & -1.6 \\
\hline 13 & $12 / \mathrm{F}$ & - & 0.6 & - & -2.8 \\
\hline 14 & $10 / \mathrm{M}$ & - & - & - & -2.7 \\
\hline 15 & $14 / \mathrm{M}$ & 0.55 & -0.21 & 0.3 & -4.96 \\
\hline 16 & $15 / \mathrm{F}$ & - & - & 0.95 & 0.6 \\
\hline 17 & $16 / \mathrm{M}$ & 0.73 & -3.1 & 0.61 & -4.1 \\
\hline 18 & $12 / \mathrm{M}$ & 0.75 & -2.3 & 0.49 & -2.9 \\
\hline 19 & $17 / \mathrm{M}$ & 0.53 & -5.4 & - & - \\
\hline 20 & $15 / \mathrm{M}$ & 0.54 & -3.1 & 0.55 & -3.3 \\
\hline 21 & $17 / \mathrm{M}$ & - & - & 0.34 & -6.3 \\
\hline 22 & $18 / \mathrm{M}$ & 0.92 & -2.8 & 0.8 & -3 \\
\hline 23 & $7 / \mathrm{M}$ & 0.77 & -1.2 & 0.57 & -1.4 \\
\hline 24 & $15 / \mathrm{M}$ & 0.88 & 0.64 & 0.05 & -6.31 \\
\hline 25 & $11 / \mathrm{M}$ & 0.79 & -1.4 & 0.63 & -1.4 \\
\hline 26 & $5 / \mathrm{M}$ & - & - & 0.44 & -2.3 \\
\hline
\end{tabular}


Table 4. Individual results of densitometry in patients with a history of surgery for myelomeningocele.

\begin{tabular}{cccccc}
\hline Participant no & Age (years)/sex & $\begin{array}{c}\text { TBLH } \\
\text { BMD }\left(\mathrm{g} / \mathrm{cm}^{2}\right)\end{array}$ & Z-score & $\begin{array}{c}\text { BMD spine } \\
\left(\mathrm{g} / \mathrm{cm}^{2}\right)\end{array}$ & Z-score \\
\hline 27 & $13 / \mathrm{F}$ & 0.708 & -2.4 & 0.509 & -4.4 \\
28 & $3 / \mathrm{M}$ & 0.561 & 0.07 & 0.522 & -1.03 \\
29 & $13 / \mathrm{M}$ & - & - & 0.183 & -7.0 \\
30 & $9 / \mathrm{M}$ & 0.616 & -1.8 & 0.603 & -2.0 \\
31 & $14 / \mathrm{F}$ & 1.018 & 0.09 & 0.552 & -4.83 \\
32 & $11 / \mathrm{M}$ & 0.613 & -2.4 & 0.436 & -3.0 \\
33 & $15 / \mathrm{M}$ & 0.859 & -2.64 & 0.495 & -5.75 \\
34 & $8 / \mathrm{F}$ & 0.612 & -1.2 & 0.502 & -2.3 \\
\hline
\end{tabular}

In some of these children, osteoporosis was diagnosed according to The International Society for Clinical Densitometry (ISCD) criteria, as they met the densitometric criterion: a Z-score equal to or less than -2.0 and had suffered clinically relevant fractures: at least one vertebral fracture and 2 or more long bone fractures by 10 years of age or 3 fractures by 19 years of age [9] [10]. The difference between TBLH BMD Z-score and Spine BMD Z-score was connected with place of measurement and patient's clinical condition (anxiety, skeletal abnormalities, history of fractures). Vertebral fractures occurred in two boys with cerebral palsy, while femoral fractures were most commonly seen in the group of patients with a history of myelomeningocele.

Henderson et al. assessed 619 children with muscular dystrophy and cerebral palsy and showed that the risk of bone fractures increased with declining BMD $\mathrm{Z}$-score. Each decrease in Z-score of 1 increased the risk of bone fracture by $6 \%$ to $15 \%$ [2], which is difficult to demonstrate in our patients because we have not presented continuous observations in our paper. No bone fractures were reported in our children with muscular dystrophy, although 2/7 were found to have low bone mineral density (a Z-score of less than -2.0 ), while three of them, with Duchenne muscular dystrophy were receiving glucocorticosteroids.

Glucocorticosteroid treatment, in addition to low mobility, negatively impacts bone mass in patients with muscular dystrophy, as pointed out by Houston et al. and Söderpalm et al. [11] [12]. It should be noted, however, than our study group included not only patients with Duchenne muscular dystrophy (DMD), but also with spinal muscular atrophy and progressive dystrophy, which may be of significance when comparing the results with literature data in which patients with DMD predominate [4] [11] [12].

King et al. associated the tendency for fractures in Duchenne muscular dystrophy not only with low BMD but also with decreased bone dimensions [13].

Vertebral fractures in boys with DMD were frequent after the first long bone fracture reported by Ma et al. 4/10 boys with long bone fracture later sustained a 
total of 27 incident vertebral fractures and these results support inclusion of a lateral spine radiograph at the time of glucocorticosteroids initiation as a part of routine bone health monitoring in DMD [14]. Bone fractures were not diagnosed in our children with Duchenne muscular dystrophy, two of whom were treated with glucocorticosteroids.

Of note is the low concentration of the hepatic metabolite of vitamin $\mathrm{D}$, which we found in many $(>80 \%)$ of the disabled children. This may be a result of their "homebound" lifestyle (non-walkers, non-ambulatory). This finding is consistent with observations reported by many other authors [4] [12] [15]. A possible explanation for vitamin $\mathrm{D}$ deficiency in these patients are the following problems that co-exist with neuromuscular and neurodevelopmental disorders in these patients: gastrointestinal motility disorders, nutritional deficiencies and treatment with drugs that affect vitamin $\mathrm{D}$ metabolism (e.g. anticonvulsive drugs) [1] [14] [16].

We also evaluated in our study the patient's skeletal system condition after surgery for myelomeningocele. In this group of patients, low bone mass was accompanied by vitamin $\mathrm{D}$ deficiency, although fractures occurred only in the bones of the lower extremities. These findings are consistent with those reported in very few publications identified in the literature [16] [17].

According to the literature and our own observations, a low or absent spontaneous activity of the patients due to the underlying condition (cerebral palsy, muscular dystrophy, history of surgery for myelomeningocele) is the most permanent factor that leads to low bone mineral mass, which increases the risk of fractures [2] [4] [5] [15] [16] [18]. It is noteworthy in our study population that the low bone mineral density was not always associated with bone fracture, and vertebral fractures were only reported by two patients. It may well be that these children presented for evaluation early enough for us to be able to implement preventive measures following densitometry (calcium and vitamin D supplementation) and to consequently prevent bone fractures.

The diagnosis of secondary osteoporosis in children significantly impacts their quality of life, hence the treatment with calcium, vitamin $\mathrm{D}$ and bisphosphonates [5] [10] [11] [16] [19]. These treatments increase bone mineral density and, as a result, reduce the risk of fractures. Beneficial effects of bisphosphonates are reported in patients with cerebral palsy and Duchenne muscular dystrophy [19] [20]. These drugs are mainly used in disabled patients undergoing glucocorticosteroid treatment who have suffered bone fractures [21].

They have also been used by us in 10 disabled children and adolescents with secondary osteoporosis, which will be addressed in a future publication.

\section{Conclusion}

Bone densitometry should be included in the standard of care for children with chronic neurological syndromes, and early detection of low bone mass should be an indication for treatment with calcium and vitamin $\mathrm{D}$. 


\section{Funding}

This work was supported by Medical University of Lodz, Poland (503/1-090-02/503-11-001 and 503/1-056-01/503-11-003).

\section{References}

[1] Bianchi, M.L., Leonard, M.B., Bechtold, S., Högler, W., Mughal, M.Z., Schönau, E., Sylvester, F.A., Vogiatzi, M., van den Heuvel-Eibrink, M.M. and Ward, L. (2014) Bone Health in Children and Adolescents with Chronic Diseases That May Affect the Skeleton: The 2013 ISCD Pediartic Official Positions. Journal of Clinical Densitometry, 17, 281-294. https://doi.org/10.1016/j.jocd.2014.01.005

[2] Henderson, R.C., Berglund, L.M., May, R., Zemel, B.S., Grossberg, RI., Johnson, J., Plotkin, H., Stevenson, R.D., Szalay, E., Wong, B., Kecskemethy, H.H. and Harcke, H.T. (2010) The Relationship between Fractures and DXA Measures in the Distal Femur of Children and Adolescents with Cerebral Pulsy or Muscular Dystrophy. Journal of Bone and Mineral Research, 25, 520-526. https://doi.org/10.1359/jbmr.091007

[3] Jones, A.R., Zacharin, M.R., Cameron, F.J. and Simm, P.J. (2015) Bone density Assessment in Tertiary Paediatric Centre over 13 Years: Referral Patterns and Limitations. Journal of Paediatrics and Child Health, 51, 608-613.

https://doi.org/10.1111/jpc.12789

[4] Bianchi, M.L., Mazzanti, A., Galbiati, E., Saraifoger, S., Dubini, A., Cornelio, F. and Morandi, L. (2003) Bone Mineral Density and Bone Metabolism in Duchenne Muscular Dystrophy. Osteoporosis International, 14, 761-767.

https://doi.org/10.1111/jpc.12789

[5] Iasaki, T., Nonoda, Y. and Ishii, M. (2012) Long-Term Outcomes of Children and Adolescents Who Had Cerebral Palsy with Secondary Osteoporosis. Current Medical Research and Opinion, 28, 737-747. https://doi.org/10.1185/03007995.2011.645562

[6] Kułaga, Z., Różdżyńska, A. and Palczewska, I. (2010) Percentile Charts of Height, Body Mass and Body Mass Index in Children and adolescents in Poland-Results of the OLAF Study. Standardy Medyczne, 7, 690-706.

[7] Jongen, M.J.M.., van Ginkel, F.C., van der Vij, W.J.F., Kuiper, S., Netelenbos, J.C. and Lips, P. (1984) International Comparison of Vitamin D Metabolite Measurements. Clinical Chemistry, 30, 399.

[8] Płudowski, P., Karczmarewicz, E., Bayer, M., Carter, G., Chlebna-Sokół, D., Czech-Kowalska, J., Dębski, R., Decsi, T., Dobrzańska, A., Franek, E., Głuszko, P., Grant, W.B., Holick, M.F., Yankovskaya, L., Konstantynowicz, J., Książyk, J.B., Księżopolska-Orłowska, K,, Lewiński, A., Litwin, M., Lohner, S., Lorenc, R.S., Lukaszkiewicz, J., Marcinowska-Suchowierska, E., Milewicz, A., Misiorowski, W., Nowicki, M., Povoroznyuk, V., Rozentryt, P., Rudenka, E., Shoenfeld, Y., Socha, P., Solnica, B., Szalecki, M., Tałałaj, M., Varbiro, S. and Żmijewski, M.A. (2013) Practical Guidelines for the Supplementation of Vitamin D and the Treatment of Deficits in Central Europe-Recommended Vitamin D Intakes in the General Population and Groups at Risk Vitamin D Deficiency. Endokrynologia Polska, 64, 1-9. https://doi.org/10.5603/EP.2013.0012

[9] Gordon, C.M., Leonard, M.B. and Zemel, B.S. (2014) 2013 Pediatric Position Development Conference: Executive Summary and Reflections. Journal of Clinical Densitometry, 17, 219-224. https://doi.org/10.1016/j.jocd.2014.01.007 
[10] Bachrach, L.K. and Gordon, C.M. (2016) Section on Endocrinology. Bone Densitometry in Children and Adolescents. Pediatrics, 138, e1-e7. https://doi.org/10.1542/peds.2016-2398

[11] Houston, C., Mathews, K. and Shibli-Rahhal, A. (2014) Bone Density and Alendronate Effects in Duchenne Muscular Dystrophy Patients. Muscle \& Nerve, 49, 506-511. https://doi.org/10.1002/mus.23948

[12] Soderpalm, A.C., Magnusson, P., Ahlander, A.C., Kalsson, J., Kroksmark, A.K., Tulinius, M. and Swolin-Eide, D. (2007) Low Bone Mineral Density and Decreased Bone Turnover in Duchenne Muscular Dystrophy. Neuromuscular Disorders, 17, 919-928. https://doi.org/10.1016/j.nmd.2007.05.008

[13] King, W.M., Kissel, J.T., Visy, D., Goel, P.K. and Matkovic, V. (2014) Skeletal Health in Duchenne Dystrophy: Bone-Size and Subcranial Dual-Enegy X-Ray Absorptiometry Analyses. Muscle \& Nerve, 49, 512-519.

https://doi.org/10.1002/mus.23963

[14] Ma, J., McMillan, H.J., Karagüzel, G., Googin, C., Wasson, J., Matzinger, M.A., DesClouds, P., Cram, D., Page, M., Konji, V.N., Lentle, B. and Ward, L.M. (2017) The Time to and Determinants of First Fractures in Boys with Duchenne Muscular Dystrophy. Osteoporosis International, 28, 597-608.

https://doi.org/10.1007/s00198-016-3774-5

[15] Finbraten, A.K., Syversen, I.J., Skranes, J., Andersen, G.L., Stevenson, R.D. and Vik T. (2015) Bone Mineral Density and Vitamin D Status in Ambulatory and Non-Ambulatory Children with Cerebral Palsy. Osteoporosis International, 26, 141-150. https://doi.org/10.1007/s00198-014-2840-0

[16] Boyce, A.M., Tosi, L.L. and Paul, S.M. (2014) Bisphoshponate Treatment for Children with Disabling Conditions. $P M \& R, 6,427-436$. https://doi.org/10.1016/j.pmrj.2013.10.009

[17] Martinelli, V., Dell'Atti, C., Ausili, E., Federic, E., Magarelli, N., Leone, A., Massimi, L., Di Rocco, C., Bonomo, L. and Rendeli, C. (2015) Risk of Fracture Prevention in Spina Bifida Patients: Correlation between Bone Mineral Density, Vitamin D, and Electrolyte Values. Child s Nervous System, 31, 1361-1365. https://doi.org/10.1007/s00381-015-2726-2

[18] Chlebna-Sokół, D., Kiliańska, A., Rusińska, A. and Loba-Jakubowska, E. (2006) Disability of Locomotor System in Bone Metabolic Diseases-Experiences of Department of Paediatric Propedeutics and Bone Metabolic Diseases. Przegląd Pediatryczny, 36, 277-280.

[19] Kim, M.J., Kim, S.N., Lee, I.S., Chung, S., Lee, J. and Koh, S.E. (2015) Effects of Bisphosphonates to Treat Osteoporosis in Children with Cerebral Palsy: A Meta-Analysis. Journal of Pediatric Endocrinology and Metabolism, 28, 1343-1350.

[20] Sbrocchi, A.M., Rauch, F., Jacob, P., McComick, A., McMillan, H.J., Matzinger, M.A. and Ward, L.M. (2012) The Use of Intravenous Bisphosphonate Therapy to Treat Vertebral Fractures Due to Osteoporosis among Boys with Duchenne Muscular Dystrophy. Osteoporosis International, 23, 2703-2711. https://doi.org/10.1007/s00198-012-1911-3

[21] Birnkrant, D.J., Bushby, K., Bann, C.M., Alman, B.A., Apkon, S.D., Blackwell, A., Case, L.E., Cripe, L., Hadjiyannakis, S., Olson, A.K., Sheehan, D.W., Bolen, J., Weber, D.R. and Ward, L.M. (2018) Diagnosis and Management of Duchenne Muscular Dystrophy, Part 2: Respiratory, Cardiac, Bone Health, and Orthopaedic Management. The Lancet Neurology, 17, 347-361. https://doi.org/10.1016/S1474-4422(18)30025-5 